\title{
REVIEW
}

\section{Male factor infertility and ART}

\author{
Herman Tournaye
}

For years, the management and treatment of male factor infertility has been 'experience' and not 'evidence' based. Although not evidence-based, current clinical practice involves extensive use of assisted reproductive techniques (ART). Where specific treatments are not indicated or have failed, ART have become popular adjunctive treatments for alleviating male factor infertility. According to the limited evidence available, intrauterine insemination (IUI) may be considered as a first-line treatment in a couple in which the female partner has a normal fertility status and at least $1 \times 10^{6}$ progressively motile spermatozoa are recovered after sperm preparation. If no pregnancy is achieved after 3-6 cycles of IUI, optimized in vitro fertilization (IVF) can be proposed. When less than $0.5 \times 10^{6}$ progressively motile spermatozoa are obtained after seminal fluid processing or sperm are recovered surgically from the testis or epididymis, intracytoplasmic sperm injection (ICSI) should be performed. Although the outcome of no other ART has ever been scrutinized as much before, no large-scale 'macroproblems' have as yet been observed after ICSI. Yet, ICSI candidates should be rigorously screened before embarking on IVF or ICSI, and thoroughly informed of the limitations of our knowledge on the hereditary aspects of male infertility and the safety aspects of ART. Asian Journal of Andrology (2012) 14, 103-108; doi:10.1038/aja.2011.65; published online 19 December 2011

Keywords: artificial; intracytoplasmic sperm injection; insemination; in vitro fertilization; male infertility; sperm

\section{INTRODUCTION}

In contrast to women, only a limited number of men with primary male factor infertility have potentially treatable conditions. Moreover, meta-analyses show that current empirical medical treatments for unexplained male infertility are not beneficial. ${ }^{1,2}$ However, assisted reproductive techniques (ART) are perceived as being more successful than any other empirical option. When non-empirical or specific, well-defined treatments with proven benefit have not been successful in a given individual with male factor infertility, ART may be used as second-line therapy. In both circumstances, 'unexplained' and 'explained' male factor infertility, optimization of the female partner is the first action to be taken. When empiric or specific treatment improves sperm quantity or quality to a limited degree, but not enough for natural conception, this may be enough to allow the use of less intensive adjunctive techniques such as intrauterine insemination (IUI) or in vitro fertilization (IVF), and avoid intracytoplasmic sperm injection (ICSI) — clearly, an often unappreciated benefit.

ART aims at increasing the probability of fertilization by bringing the spermatozoa closer to (or even within) the oocyte(s), thereby bypassing some functional deficits of the male gametes. IUI and IVF- embryo transfer are the most popular techniques for treating male factor infertility. In the latter, the rate of fertilization is enhanced by microinjecting one single spermatozoon directly into the oocyte's cytoplasm, i.e. ICSI. ICSI allows the successful use of ejaculated, epididymal or testicular spermatozoa to obtain fertilization in vitro.

\section{WHICH ART SHOULD BE USED TO CIRCUMVENT MALE FACTOR INFERTILITY?}

Defining when and which technique to choose remains an important issue. Although good prospective evidence is lacking, often the choice of which ART is employed to circumvent male factor infertility is made according to sperm parameters, i.e., total motile count (TMC) either before or after sperm preparation. TMC is the total number of spermatozoa in the ejaculate or prepared sample (volume $\times$ concentration) multiplied by the percentage of progressive motile spermatozoa. If the native, unprocessed semen sample contains a TMC of at least $1 \times 10^{6}-3 \times 10^{6}$, corresponding to mild to moderate oligoasthenoteratozoospermia, IUI can be proposed as a first-line approach, when at least $0.8 \times 10^{6}$ motile sperm can be recovered after preparation, which will not always be the case in this subgroup. ${ }^{3}$

Compared with IVF with or without ICSI, there is good evidence that IUI is a cost-effective treatment option that should be initiated before more invasive and expensive treatment alternatives are offered. ${ }^{4,5}$ As a recent meta-analysis has shown, in cases of male factor infertility, if the post-processing TMC is $<1 \times 10^{6}$, IUI has no benefit with little expectation of conception. ${ }^{3}$ Instead of IVF, ICSI or a combination of both, i.e. a split set-up, may be the initial suggestion to the couple.

\section{INTRAUTERINE INSEMINATION FOR MALE FACTOR INFERTILITY}

Although there are no studies available in the literature demonstrating increased live-birth rates after IUI in male factor infertility, six randomized controlled trials (RCTs) showed a significant increase in pregnancy rates after IUI, compared to timed intercourse in cases of male factor infertility. ${ }^{6}$ When used for unexplained infertility, ovarian superovulation coupled with IUI will increase the pregnancy rate, but level 1 evidence does not show this to be true when ovarian superovulation coupled with IUI is applied for male factor infertility. ${ }^{7-9}$ However, timing by either detecting the onset of the luteinizing hormone surge or administering human chorionic gonadotropin or 
recombinant human chorionic gonadotropin is beneficial (level 1 evidence).${ }^{10}$ Both timing methods are of a similar value,${ }^{11}$ but human chorionic gonadotropin injection has to be performed when the dominant follicle(s) reach a mean diameter of $16-18 \mathrm{~mm}$ and is followed by insemination $36-42 \mathrm{~h}$ later. When a spontaneous leutenizing hormone peak is detected in serum, insemination has to be scheduled $24 \mathrm{~h}$ later, and when detected in urine, $18 \mathrm{~h}$ afterwards.

There is still some controversy whether a second insemination per cycle increases the chances for conception. When combining the conclusions of six RCTs in regard to male factor cases, a double insemination strategy appears to be of some benefits. However, this conclusion is suspect, as it is based upon one large RCT with extremely high pregnancy rates per cycle and its conclusion is contradictory to those from the five other RCTs, obviously casting some doubt on the final recommendation. ${ }^{12}$

While good evidence is available that at least one million motile spermatozoa have to be inseminated at IUI, limited evidence is available on how to prepare semen for IUI. A meta-analysis authored by Boomsma et al. ${ }^{13}$ shows that, while gradient techniques yield the highest recovery rates, no semen preparation technique appears superior when compared to others that are also in common use. Whether exogenous agents used to promote sperm motility, sperm capacitation and the acrosome reaction can improve the chances for conception after IUI for male factor infertility also remains inconclusive. For example, even the addition of platelet-activating factor, a signaling phospholipid known to be involved in regulation of sperm-fertilizing potential, to sperm wash used for IUI does not result in significantly higher pregnancy rates. ${ }^{14}$

According to retrospective cohort studies, most pregnancies achieved with IUI in women under 37 years of age will occur during the first 3-4 treatment cycles. ${ }^{15,16}$ While this highlights that female age plays an important role in the success of IUI, including IUI for male factor infertility, ${ }^{4,17,18}$ there are few data available exploring the effect of paternal age on IUI outcome. For spontaneous conception, increased paternal age has no profound effect whenever the female partner is young, but time to pregnancy is reported to be longer when compared to younger men. ${ }^{19,20}$ However, when the female partner is also of advanced age, there seems to be a synergistic adverse effect of paternal age, as reported in a large, retrospective, multicenter study. ${ }^{21}$ Retrospective data suggest that the synergistic effect described for spontaneous conception may also exist in IUI, i.e. no age effect when an older man and a young female partner employ IUI, but reduced reproductive success when the female partner is older. ${ }^{22}$ Finally, a recent retrospective study reported not only a decline in pregnancy rate, but also an increased miscarriage rate after IUI in couples with advanced paternal age. Although more than 17000 IUI cycles were analyzed, this study did not properly control confounding factors, and hence, the conclusions are controversial. ${ }^{23}$

\section{IVF OR ICSI FOR MALE FACTOR INFERTILITY}

While IVF was introduced in the late 1970s as a treatment for tubal infertility, it quickly became apparent that it was also an excellent therapeutic option for male subfertility. ${ }^{24}$ It is important to heed the advice of a few small RCTs, however, that caution against resorting to IVF too early in the evaluation and management of male factor infertility. When early IVF is compared to conventional treatment, chances of pregnancy achievement may not be improved, and total costs may be higher. ${ }^{4,25,26}$ It is reasonable, therefore, to escalate treatment to IVF, when no conception has occurred after 3-4 IUI cycles in couples with moderate male factor subfertility with at least one million motile sperm after semen preparation. A larger question arises, however, 'For male factor infertility, is there still a role for IVF in the era of ICSI?'.

The prevalence of complete fertilization failure after conventional IVF is reported to be as high as $50 \% .{ }^{27,28}$ Complete fertilization failure is an unwanted event not only because of the obvious (no hope of pregnancy that cycle) impact on the couple, but also because of the negative, distressing, psychological impact on the couple. The causes of total fertilization failure during standard IVF are related to either oocyte, sperm or laboratory factors; this is also true for ICSI cycles in which complete fertilization failure occurs in less than $3 \%$ of started cycles. ${ }^{29}$ Although ICSI has been put forth as the most robust technique for achieving fertilization in an IVF program, the aim of reproductive medicine and the specialists that practice it should always be to use the simplest and least expensive procedure with the greatest longterm chance of healthy children (Figure 1).

The cutoff values used to decide between conventional IVF and ICSI are generally experience-based. As for IUI, the TMC (in the native semen sample or after sperm preparation) and sperm morphology (strict criteria) have been used as criteria for determining if conventional IVF treatment will be recommended to the couple. In this regard, Kastrop et al. ${ }^{30}$ proposed a minimum motile count of at least one million spermatozoa in the native semen sample. Other authors use the motile progressive count after sperm preparation as their criterion, with suggested lower limits of one million ${ }^{31}$ to 0.5 million progressive motile spermatozoa ${ }^{32}$ or even 0.2 million motile progressive spermatozoa. ${ }^{33}$ When morphology is used as a guage, $5 \%$ normal forms is the cutoff value, below which poor fertilization after conventional IVF is anticipated. ${ }^{34}$ Occasionally, a combination of morphology and motile count is analyzed. Plachot et al. ${ }^{35}$ propose that at least 0.5 million normal, progressively motile sperm per milliliter must be present in the ejaculate in order to recommend conventional IVF. Contemporary strategies for deciding between IVF and ICSI are either formulated using these experience-based, preset cutoff values or created with the assumption that ICSI is the more robust insemination technique. A meta-analysis focusing only on border-line oligoasthenoteratozoospermia concluded that whether fertilization occurs or not during standard IVF is highly dependent on the numbers of motile spermatozoa used for insemination. ${ }^{36}$ Subanalysis of three RCTs in which a high insemination concentration was used could not show any significant benefit of ICSI over IVF. Although the current evidence is limited, the conclusion of independent two meta-analyses calls for caution when promoting ICSI for moderate male factor infertility. ${ }^{36,37}$

Before ICSI was introduced, sperm function tests were used in an attempt to test the fertilizing potential. While sperm function tests can

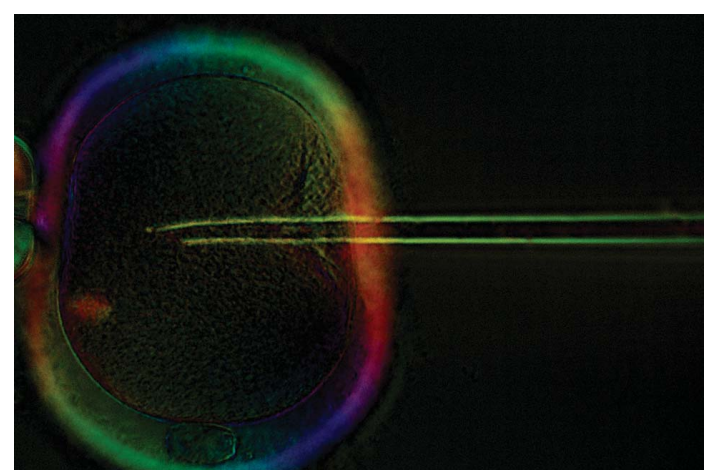

Figure 1 Intracytoplasmic sperm injection. 
identify certain deficiencies of sperm function, they are subject to both inter- and intra-observer variability and show limited sensitivity. A recent paper critically reviewed their use in ART. ${ }^{38}$ Therefore, in the ICSI era, their role became obsolete and many of these tests are now categorized as 'research procedures'. 39

An alternative strategy for making the IVF or ICSI choice is to treat long-standing moderate male factor infertility with a split IVF-ICSI cycle, in which sibling oocytes are either inseminated conventionally or micro-injected. Although there is still inconclusive evidence on the role of this tactic, a split IVF-ICSI approach may prevent complete fertilization failure in 1 out of 4 cycles where conventional IVF is applied for moderate male factor infertility and where even a high insemination concentration is applied..$^{40,41}$

\section{ABSOLUTE INDICATIONS FOR ICSI IN MALE FACTOR INFERTILITY}

Although there is no good clinical evidence available, there are well accepted, absolute indications for ICSI: use of surgically retrieved testicular and epididymal sperm, use of immotile, but viable, ejaculate spermatozoa (e.g. flagellar dyskinesia and immotile cilia syndromes) and use of round-headed spermatozoa (globozoospermia). In addition, some authors believe that the presence of significant levels of antisperm antibodies is an indication to always perform ICSI, ${ }^{42,43}$ despite a recent meta-analysis concluding that there is no benefit of ICSI over IVF in cases of antisperm antibody-mediated male factor infertility. ${ }^{44}$ For cryopreserved sperm from cancer patients, no prospective comparative studies pitting the use of IVF versus ICSI are available in the literature. However, based on retrospective case series, it may be prudent that for most of these patients, given the poor quality of sperm cryopreserved, the post-thaw sperm damage that may occur and the limited numbers of spermatozoa available, ICSI should be the method of choice when assisted reproduction is indicated. ${ }^{45-48}$

Complete asthenozoospermia, i.e., 100\% immotile spermatozoa in the ejaculate, is reported at a frequency of one out of 5000 men. It is extremely important to determine the underlying etiology, e.g., primary ciliary dyskinesia (spermatozoa are immotile but viable) or necrozoospermia (spermatozoa are non-viable as may occur in near-complete occlusion of the vas or ejaculatory ducts). In the former category, electron microscopy is the gold standard to diagnose specific sperm defects. ${ }^{49}$ Correction should be carried out when possible (e.g., transurethral resection of the ejaculatory ducts in partial ejaculatory duct obstruction). Injection of uncharacterized immotile sperm makes fertilization after ICSI unpredictable and decreases both fertilization and pregnancy rates. ${ }^{50,51}$ When no motile spermatozoa are found in the ejaculate, the patient should produce a second ejaculate. In most patients, the second semen sample often contains a few motile spermatozoa for use with ICSI. In patients with absolute asthenozoospermia, even after extensive processing of the semen specimen(s), different strategies can be applied to improve ICSI outcome. Immotile but vital spermatozoa may be selected by a hypo-osmotic swelling test. Since the hypo-osmotic swelling test depends, in part, on the sperm tail membrane, it is not very useful when there are anatomical sperm tail deficiencies, functional sperm tail and flagellar defects. ${ }^{52}$ Apart from the hypo-osmotic swelling test, additional corrective measures can be tried, such as exposure of the sperm to pentoxifylline, application of laser-assisted immotile sperm selection or the use of a birefringence PolScope. ${ }^{52}$ If only dead sperm are present in repeated ejaculates (necrozoospermia), viable spermatozoa may be recovered from a testicular biopsy, and lead to normal fertilization and pregnancies after ICSI. $^{53}$
Globozoospermia is an uncommon cause of male sterility, affecting $0.1 \%$ of all patients suffering from male infertility, and is characterized by the complete absence of the acrosomal vesicle, i.e. acrosomal aplasia or agenesis, hence the synonym round-headed sperm. ${ }^{54}$ Globozoospermia is the morphological end result of disturbed spermiogenesis and, recently, genetic etiologies have been described. ${ }^{55,56}$ Various case reports have detailed the birth of ICSI-conceived offspring using round-headed acrosomeless spermatozoa, but in consecutive case series, the results after ICSI are poor and unpredictable, even when artificial oocyte activation with calcium ionophore is applied. ${ }^{57}$

Apart from globozoospermia and structural abnormalities involving the midpiece or sperm tail, as mentioned above, the impact of teratozoospermia on the outcome after ICSI remains limited. Minor structural defects may be diverse and not present in all spermatozoa. Hence, functional spermatozoa will likely be injected in at least a portion of the oocyte pool and create a variable number of morphologically good-quality embryos and healthy offspring. A meta-analysis of studies focusing on teratozoospermia concluded that no decrease in the probability of conception is observed after ICSI using sperm from men with isolated teratozoospermia. ${ }^{58}$ However, when only embryos resulting from ICSI using morphologically abnormal spermatozoa are transferred, implantation rates are lower. ${ }^{59}$

Loss of DNA integrity may also have an impact on ICSI outcome. ${ }^{60}$ Unfortunately, there are no real-time methods available to discard spermatozoa with ultrastructural tail deficiencies, DNA damage or chromosomal instability. Yet novel methods to improve selection of spermatozoa for ICSI have been introduced. In the technique of intracytoplasmic morphologically selected sperm injection, spermatozoa are selected by high-power magnification (about $\times 6000$ ). Based on the few studies available in the literature, a recent, albeit premature, meta-analysis concluded that intracytoplasmic morphologically selected sperm injection may significantly improve implantation and pregnancy rates while also reducing miscarriage rates after ICSI. ${ }^{61}$

Finally, a technique that depends on binding of spermatozoa to solid-state hyaluronan has been introduced in an effort to select mature spermatozoa with lower levels of chromosomal instability for use in conjunction with ICSI. ${ }^{62}$ Since the bound mature spermatozoa have to be 'harvested' from a Petri dish coated with solidstate hyaluronan, this selection method has been named 'PICSI'. Unfortunately, to date, no data from RCTs are available in order to evaluate the benefit from this novel method.

\section{AZOOSPERMIA AND ICSI}

ICSI has changed the treatment of some forms of azoospermia completely. In patients with obstructive azoospermia in whom surgical correction is not possible or has failed, spermatozoa may be recovered from either the epididymis or the testis. Different surgical techniques including microsurgical epididymal sperm aspiration, percutaneous epididymal sperm aspiration, testicular sperm extraction (TESE), testicular sperm aspiration and fine-needle aspiration of the testis have all been described. ${ }^{63}$ A Cochrane meta-analysis on surgical sperm retrieval techniques concludes that there is insufficient evidence to recommend any specific sperm retrieval technique and that the least invasive technique should be used. ${ }^{64}$

Aspiration methods are usually simple and less invasive, and can be repeatedly performed under local anesthesia. In men with normal spermatogenesis, e.g., men with an irreparable vasectomy or postinfectious obstruction, or men with congenital absence of the vas deferens, motile spermatozoa can be harvested from either the epididymis or the testis. When epidydimal sperm are to be obtained, 
motile fractions must be recovered, i.e., spermatozoa with very low levels of DNA damage, so as not to jeopardize the success rate of the coincident ICSI cycle. When motile spermatozoa are used, no differences in fertilization rates or live-birth rates are observed between epididymal and testicular sperm used for ICSI, ${ }^{65}$ but epididymal spermatozoa can be more easily cryopreserved. As for ejaculated sperm, ${ }^{66}$ in terms of the live-birth rate, there are again no differences between using cryopreserved epididymal or using fresh epididymal sperm for ICSI. ${ }^{64}$ Therefore, when cryopreservation is required, percutaneous epididymal sperm aspiration is the method of choice, followed by TESE, whenever percutaneous epididymal sperm aspiration fails. When cryopreservation is not required, fine-needle aspiration can be performed, being a minimally invasive 'no-scar' technique.

For men suffering from non-obstructive azoospermia (NOA) in need of ICSI, TESE is the best choice to recover sperm, as it provides the highest sperm recovery rate. Although technically more demanding, a benefit may be seen with a microsurgically guided technique, i.e., micro-TESE. Retrieval rates in non-obstructive azoospermic patients are between $40 \%$ and $50 \%$. However, they vary between reports because of re-allocation of successful patients or inclusion of patients with hypospermatogenesis and patients with slightly elevated folliclestimulating hormone levels with no confirmatory histological diagnosis available. Even in men persistently azoospermic after cancer treatment, including ablative chemotherapy, testicular spermatozoa may be recovered for ICSI. ${ }^{67}$ Lastly, in adult azoospermic 47,XXY Klinefelter patients, spermatozoa can be recovered for ICSI. ${ }^{68,69}$ Apart from a multiple biopsy approach, the most important factor to improve sperm recovery from testicular specimens is the microscopic assessment of the wet preparation and the concomitant application of erythrocyte-lysing buffer and/or enzymatic digestion. ${ }^{70,71}$

In men with NOA, including 47,XXY males, there is controversy on the timing of TESE relative to the cycle of ICSI. ${ }^{72}$ Since not all cryopreserved TESE samples will yield spermatozoa for ICSI after thawing, ${ }^{73}$ it may be preferable to perform the sperm retrieval on the day of oocyte pick-up. However, since more than half of NOA men will not have sperm recovered, except when undergoing repeat TESE, ${ }^{74}$ a pointless ovarian stimulation and oocyte aspiration will occur. Recovering sperm by TESE the day before oocyte aspiration must also be avoided, because testicular sperm may accumulate DNA damage overnight and should thus be injected without delay. ${ }^{75}$ If couples accept ICSI with donor sperm as a back-up, then TESE can be scheduled on the day of oocyte aspiration. Alternatively, unfertilized oocytes can now be safely cryopreserved for ICSI using donor sperm at a later stage. $^{76}$

\section{OUTCOMES AFTER ICSI}

In order to provide ICSI candidate couples a more accurate prognosis, they should be preferentially informed about cumulative live-birth rates. Unfortunately, there are only a few large studies with cumulative live-birth rates as an outcome measure. According to them, about $60 \%$ of couples in whom the female partner is younger than 37 years of age will achieve childbirth within 4 cycles. ${ }^{77,78}$ However, in women aged over 37 years, this figure decreases to $20 \% .^{79}$ Studies reporting on cumulative delivery rates in couples where testicular sperm was used are even more scarce. In couples in whom the male partner suffers from obstructive azoospermia, the cumulative chance for a delivery after 3 cycles is reported to be $35 \%$, but without drop-out, this figure would be expected to be around $50 \% .{ }^{79}$ Men suffering from NOA undergoing TESE are to be counseled that not only are the sperm recovery rates limited but also the fertilization, implantation and conception rates are decreased compared to men with normal spermatogenesis. ${ }^{65,80}$ For example, Osmanagaoglu et al. ${ }^{81}$ reported that the cumulative chance of fathering a child after 3 cycles was only $17 \%$ in a group of men with NOA, once spermatozoa were obtained for ICSI. When omitting the high drop-out rate of $75 \%$, this figure was still limited to $30 \% .{ }^{81}$ Consecutive case series, reporting on the cumulative success rates in couples combining the TESE retrieval rate and the ICSI delivery rate for couples with NOA, are unfortunately not currently available in the literature.

Since its introduction, ICSI has generated much controversy concerning its safety, mainly because of concerns about potential damage to the cytoskeleton and meiotic spindle from the process itself, deleterious modifications that may occur in genomic imprinting and transmission of genetic risks carried by candidate patients. ${ }^{82,83}$ According to different cohort studies, the prevalence of major congenital malformations after ICSI is comparable to the major congenital malformation rate as reported for conventional IVF and, reassuringly, even large-population studies. ${ }^{84-86}$ Moreover, because of the greater scrutiny to which ICSI children are subjected, any difference between ICSI, IVF and spontaneous conception may not be noteworthy. However, the mean sex chromosome aneuploidy rate after ICSI $(0.8 \%)$ is significantly higher than in the general population $(0.2 \%) .{ }^{87}$ Neither obstetric outcome of ICSI pregnancies nor child development of ICSI offspring was different from conventional IVF and not influenced by sperm origin or quality. ${ }^{88,89}$ When epididymal sperm is used for ICSI, stillbirths or congenital malformations are not more prevalent in comparison to IVF and ICSI using ejaculated sperm, while cognitive development was also similar. ${ }^{90,91}$ While aneuploidy screening on embryos obtained after ICSI for NOA showed increased aneuploidy and mosaicism, ${ }^{92}$ and karyotypes of miscarriages occurring after TESE-ICSI showed higher aneuploidy rates than expected, ${ }^{93}$ the few publications focusing on the outcome of children born after ICSI using testicular sperm conclude that no significant differences exist between ICSI using ejaculated spermatozoa or ICSI using testicular spermatozoa in terms of birth weight, perinatal mortality and major malformation rate. ${ }^{90,91,94-96}$ Subgroup analysis on children born from men with NOA showed no increase in malformation and early perinatal mortality rates in comparison to the rates observed in ICSI children after using ejaculated sperm. Given the limited numbers of children being evaluated and the doubts about the validity of data from many reports because of potential bias, e.g., background risk factors, comparison with fertile controls and overscrutinizing of ICSI pregnancies, further follow-up is certainly recommended, and both IVF and ICSI candidate parents should be informed about the uncertainties concerning the safety of these techniques in regards to their future offspring. In addition, candidate patients need genetic testing prior to ICSI, not only for pure diagnostic reasons, but also to prevent the transmission of genetic traits associated with their infertility problem.

\section{COMPETING FINANCIAL INTERESTS}

The author declares no competing financial interests.

1 O'Donovan PA, Vandekerckhove P, Lilford RJ, Hughes E. Treatment of male infertility: is it effective? Review and meta-analyses of published randomized controlled trials. Hum Reprod 1993; 8: 1209-22.

2 Kamischke A, Nieschlag E. Analysis of medical treatment of male infertility. Hum Reprod 1999; 14 (Suppl 1): 1-23.

3 van Weert JM, Repping S, van Voorhis BJ, van der Veen F, Bossuyt PM et al. Performance of the postwash total motile sperm count as a predictor of pregnancy 
at the time of intrauterine insemination: a meta-analysis. Fertil Steril2004; 82: 612 20.

4 Goverde AJ, McDonnell J, Vermeiden JP, Schats R, Rutten FF et al. Intrauterine insemination or in-vitro fertilisation in idiopathic subfertility and male subfertility: a randomised trial and cost-effectiveness analysis. Lancet 2000; 355: 13-8.

5 Karande VC, Korn A, Morris R, Rao R, Balin M et al. Prospective randomized trial comparing the outcome and cost of in vitro fertilization with that of a traditional treatment algorithm as first-line therapy for couples with infertility. Fertil Steril 1999; 71: 468-75

6 Cohlen BJ. Should we continue performing intrauterine inseminations in the year 2004? Gynecol Obstet Invest 2004; 59: 3-13.

7 van Weert JM, Repping S, van der Steeg JW, Steures P, van der Veen F et al. IUI in male subfertility: are we able to select the proper patients? Reprod Biomed Online 2005 11: 624-31.

8 Bensdorp AJ, Cohlen BJ, Heineman MJ, Vandekerckhove P. Intra-uterine insemination for male subfertility. Cochrane Database Syst Rev 2007; (4) CD000360

9 Cohlen BJ, te Velde ER, van Kooij RJ, Looman CW, Habbema JD. Controlled ovarian hyperstimulation and intrauterine insemination for treating male subfertility: a controlled study. Hum Reprod 1998; 13: 1553-8.

10 Zreik TG, Garcia-Velasco JA, Habboosh MS, Olive DL, Arici A. Prospective, randomized, crossover study to evaluate the benefit of human chorionic gonadotropin-timed versus urinary luteinizing hormone-timed intrauterine inseminations in clomiphene citrate-stimulated treatment cycles. Fertil Steril 1999; 71: 1070-4.

11 Cantineau AE, Janssen MJ, Cohlen BJ. Synchronised approach for intrauterine insemination in subfertile couples. Cochrane Database Syst Rev 2010; (4): CD006942.

12 Cantineau AE, Heineman MJ, Cohlen BJ. Single versus double intrauterine insemination (IUI) in stimulated cycles for subfertile couples. Cochrane Database Syst Rev 2003; (1): CD003854

13 Boomsma CM, Heineman MJ, Cohlen BJ, Farquhar C. Semen preparation techniques for intrauterine insemination. Cochrane Database Syst Rev 2007; (4): CD004507.

14 Baka S, Grigoriou O, Hassiakos D, Konidaris S, Papadias K et al. Treatment of sperm with platelet-activating factor does not improve intrauterine insemination outcome in unselected cases of mild male factor infertility: a prospective double-blind randomized crossover study. Urology 2009; 74: 1025-8.

15 Aboulghar M, Mansour R, Serour G, Abdrazek A, Amin Y et al. Controlled ovarian hyperstimulation and intrauterine insemination for treatment of unexplained infertility should be limited to a maximum of three trials. Fertil Steril 2001; 75 88-91.

16 Morshedi M, Duran HE, Taylor S, Oehninger S. Efficacy and pregnancy outcome of two methods of semen preparation for intrauterine insemination: a prospective randomized study. Fertil Steril 2003; 79(Suppl 3): 1625-32.

17 Merviel P, Heraud MH, Grenier N, Lourdel E, Sanguinet P et al. Predictive factors for pregnancy after intrauterine insemination (IUI): an analysis of 1038 cycles and a review of the literature. Fertil Steril 2010; 93: 79-88.

18 de Brucker $\mathrm{M}$, Tournaye $\mathrm{H}$. The effect of age on the outcome of intrauterine insemination: a review. Facts Views Vision ObGyn 2010; 2(Suppl): 42-50.

19 Ford WC, North K, Taylor H, Farrow A, Hull MG et al. Increasing paternal age is associated with delayed conception in a large population of fertile couples: evidence for declining fecundity in older men. Hum Reprod 2000; 15: 1703-8.

20 Hassan MA, Killick SR. Effect of male age on fertility: evidence for the decline in male fertility with increasing age. Fertil Steril 2003; 79(Suppl 3)1520-7.

21 de la Rochebrochard $E$, Thonneau P. Paternal age $\geqslant 40$ years: an important risk factor for infertility. Am J Obstet Gynecol 2003; 189: 901-15.

22 Brzechffa P, Buyalos R. Female and male partner AE and menotrophin requirements influence pregnancy rates with human menopausal gonadotrophin therapy in combination with intrauterine insemination. Hum Reprod 1997; 12 29-33.

23 Belloc S, Cohen-Bacrie P, Benkhalifa M, Cohen-Bacrie M, de Mouzon J et al. Effect of maternal and paternal age on pregnancy and miscarriage rates after intrauterine insemination. Reprod Biomed Online 2008; 17: 392-7.

24 Cohen J, Fehilly CB, Fishel SB, Edwards RG, Hewitt J et al. Male infertility successfully treated by in-vitro fertilisation. Lancet 1984; 8388: 1239-40.

25 Peterson CM, Hatasaka HH, Jones KP, Poulson AM Jr, Carrell DT et al. Ovulation induction with gonadotropins and intrauterine insemination compared with in vitro fertilization and no therapy: a prospective, nonrandomized, cohort study and metaanalysis. Fertil Steril 1994; 62: 535-44.

26 Soliman S, Daya S, Collins J, Jarrell J. A randomized trial of in vitro fertilization versus conventional treatment for infertility. Fertil Steril 1993; 59: 1239-44.

27 Molloy D, Harrison K, Breen T, Hennessey J. The predictive value of idiopathic failure to fertilize on the first in vitro fertilization attempt. Fertil Steril 1991; 56: 285-9.

28 Coates TE, Check JH, Choe J, Nowroozi K, Lurie D et al. An evaluation of couples with failure of fertilization in vitro. Hum Reprod 1992; 7: 978-81.

29 Liu J, Nagy ZP, Joris H, Tournaye H, Camus M et al. Analysis of 76 total-fertilizationfailure cycles out of 2732 intracytoplasmic sperm injection cycles. Hum Reprod 1995; 10: 2630-6.

30 Kastrop PM, Weima SM, van Kooij RJ, te Velde ER. Comparison between intracytoplasmic sperm injection and in-vitro fertilization (IVF) with high insemination concentration after total fertilization failure in a previous IVF attempt. Hum Reprod 1999; 14: 65-9.
31 Fisch B, Kaplan-Kraicer R, Amit S, Zukerman Z, Ovadia J et al. The relationship between sperm parameters and fertilizing capacity in vitro: a predictive role for swim up migration. J In Vitro Fert Embryo Transf 1990; 7: 38-43.

32 Verheyen G, Tournaye H, Staessen C, de Vos A, Vandervorst M et al. Controlled comparison of conventional in-vitro fertilization and intracytoplasmic sperm injection in patients with asthenozoospermia. Hum Reprod 1999; 14: 2313-9.

33 Payne D, Flaherty SP, Jeffrey R, Warnes GM, Matthews CD. Successful treatment of severe male factor infertility in 100 consecutive cycles using intracytoplasmic sperm injection. Hum Reprod 1994; 9: 2051-7.

34 Grow DR, Oehninger S, Seltman HJ, Toner JP, Swanson RJ et al. Sperm morphology as diagnosed by strict criteria: probing the impact of teratozoospermia on fertilization rate and pregnancy outcome in a large in vitro fertilization population. Fertil Steril 1994; 62: 559-67.

35 Plachot M, Belaisch-Allart J, Mayenga JM, Chouraqui A, Tesquier L et al. Outcome of conventional IVF and ICSI on sibling oocytes in mild male factor infertility. Hum Reprod 2002; 17: 362-9.

36 Tournaye H, Verheyen G, Albano C, Camus M, van Landuyt L et al. Intracytoplasmic sperm injection versus in vitro fertilization: a randomized controlled trial and a metaanalysis of the literature. Fertil Steril2002; 78: 1030-7.

37 Hotaling JM, Smith JF, Rosen M, Muller $\mathrm{CH}$, Walsh TJ. The relationship between isolated teratozoospermia and clinical pregnancy after in vitro fertilization with or without intracytoplasmic sperm injection: a systematic review and meta-analysis. Fertil Steril 2011; 95: 1141-5

38 Muller $\mathrm{CH}$. Rationale, interpretation, validation, and uses of sperm function tests. $J$ Androl 2000; 21: 10-30

39 World Health Organization. WHO Laboratory Manual for the Examination and Processing of Human Semen, 5th ed. Geneva: World Health Organization; 2010.

40 van der Westerlaken L, Helmerhorst F, Dieben S, Naaktgeboren N. Intracytoplasmic sperm injection as a treatment for unexplained total fertilization failure or low fertilization after conventional in vitro fertilization. Fertil Steril 2005; 83: 612-7.

41 Kihaile PE, Misumi J, Hirotsuru K, Kumasako Y, Kisanga RE et al. Comparison of sibling oocyte outcomes after intracytoplasmic sperm injection and in vitro fertilization in severe teratozoospermic patients in the first cycle. Int $J$ Androl 2003; 26: 57-62.

42 Nagy ZP, Verheyen G, Liu J, Joris $H$, Janssenswillen $C$ et al. Results of 55 intracytoplasmic sperm injection cycles in the treatment of male-immunological infertility. Hum Reprod 1995; 10: 1775-80.

43 Lahteenmaki A, Reima I, Hovatta O. Treatment of severe male immunological infertility by intracytoplasmic sperm injection. Hum Reprod 1995; 10: 2824-8.

44 Zini A, Fahmy N, Belzile E, Ciampi A, Al-Hathal N et al. Antisperm antibodies are not associated with pregnancy rates after IVF and ICSI: systematic review and metaanalysis. Hum Reprod 2011; 26: 1288-95.

45 Kelleher S, Wishart SM, Liu PY, Turner L, di Pierro I et al. Long-term outcomes of elective human sperm cryostorage. Hum Reprod 00116: 2632-9.

46 Tournaye H, Goossens E, Verheyen G, Frederickx V, de Block G et al. Preserving the reproductive potential of men and boys with cancer: current concepts and future prospects. Hum Reprod Update 2004; 10: 525-32.

47 Hourvitz A, Goldschlag DE, Davis OK, Gosden LV, Palermo GD et al. Intracytoplasmic sperm injection (ICSI) using cryopreserved sperm from men with malignant neoplasm yields high pregnancy rates. Fertil Steril 2008; 90: 557-63.

48 Dohle G. Male infertility in cancer patients: review of the literature. Int J Urol 2010, 17: 327-31

49 Mobberley MA. Electron microscopy in the investigation of asthenozoospermia. $\mathrm{Br} \mathrm{J}$ Biomed Sci 2010; 67: 92-100

50 Tournaye $\mathrm{H}$. Clinical aspects of ICSI with immotile sperm. In: Hamamah S, Olivennes F, Mieusset R, Frydman R, editors. Male Sterility and Motility Disorders. New York: Springer-Verlag; 1999; 135-40.

51 Mitchell V, Rives N, Albert M, Peers MC, Selva J et al Outcome of ICSI with ejaculated spermatozoa in a series of men with distinct ultrastructural flagellar abnormalities. Hum Reprod 2006; 21 : 2065-74.

52 Ortega C, Verheyen G, Raick D, Camus M, Devroey $\mathrm{P}$ et al. Absolute asthenozoospermia and ICSI: what are the options? Hum Reprod Update 2011; 17 684-92.

53 Tournaye H, Liu J, Nagy Z, Verheyen G, van Steirteghem A et al. The use of testicular sperm for intracytoplasmic sperm injection in patients with necrozoospermia. Ferti Steril 1996; 66: 331-4.

54 Holstein AF, Schirren C, Schirren CG. Human spermatids and spermatozoa lacking acrosomes. J Reprod Fertil 1973; 35: 489-91.

55 Dam AH, Koscinski I, Kremer JA, Moutou C, Jaeger AS et al. Homozygous mutation in SPATA16 is associated with male infertility in human globozoospermia. Am J Hum Genet 2007; 81: 813-20.

56 Liu G, Shi QW, Lu GX. A newly discovered mutation in PICK1 in a human with globozoospermia. Asian J Androl 2010; 12: 556-60.

57 Tournaye H. Sperm parameters, globozoospermia, necrozoospermia and ICSI outcome. In: Filicori M, editor. Treatment of Infertility: The New Frontiers. Princeton, NJ: Communications Media for Education;1998; 259-68.

58 Hotaling JM, Smith JF, Rosen M, Muller CH, Walsh TJ. The relationship between isolated teratozoospermia and clinical pregnancy after in vitro fertilization with or without intracytoplasmic sperm injection: a systematic review and meta-analysis. Fertil Steril 2010; 95: 1141-5.

59 de Vos A, van de Velde H, Joris H, Verheyen G, Devroey P et al. Influence of individual sperm morphology on fertilization, embryo morphology, and pregnancy outcome of intracytoplasmic sperm injection. Fertil Steril 2003; 79: 42-8. 
60 Zini A, Jamal W, Cowan L, Al-Hathal N. Is sperm DNA damage associated with IVF embryo quality? A systematic review. J Assist Reprod Genet 2011; 28: 391-7.

61 Souza Setti A, Ferreira RC, Paes de Almeida Ferreira Braga D, de Cassia Savio Figueira R, laconelli A Jr et al. Intracytoplasmic sperm injection outcome versus intracytoplasmic morphologically selected sperm injection outcome: a metaanalysis. Reprod Biomed Online 2010; 21: 450-5.

62 Huszar G, Jakab A, Sakkas D, Ozenci CC, Cayli S et al. Fertility testing and ICSI sperm selection by hyaluronic acid binding: clinical and genetic aspects. Reprod Biomed Online 2007; 14: 650-63.

63 Tournaye $\mathrm{H}$. Update on surgical sperm recovery - the European view. Hum Fertil (Camb) 2010; 13: 242-6.

64 van Peperstraten A, Proctor ML, Johnson NP, Philipson G. Techniques for surgical retrieval of sperm prior to intra-cytoplasmic sperm injection (ICSI) for azoospermia. Cochrane Database Syst Rev 2008; (16): CD002807.

65 Nicopoullos J, Gilling-Smith C, Almeida PA, Norman-Taylor J, Grace I et al. Use of surgical sperm retrieval in azoospermic men: a meta-analysis. Fertil Steril 2004; 82 : 691-701.

66 Kalsi J, Thum MY, Muneer A, Pryor J, Abdullah $\mathrm{H}$ et al. Analysis of the outcome of intracytoplasmic sperm injection using fresh or frozen sperm. BJU Int 2011; 107: 1124-8.

67 Hsiao W, Stahl PJ, Osterberg EC, Nejat E, Palermo GD et al. Successful treatment of postchemotherapy azoospermia with microsurgical testicular sperm extraction: the Weill Cornell experience. J Clin Oncol 2011; 29: 1607-11.

68 Tournaye H, Staessen C, Liebaers I, van Assche E, Devroey P et al. Testicular sperm recovery in 47,XXY Klinefelter patients. Hum Reprod 1996; 11: 1644-9.

69 Bakircioglu ME, Ulug U, Erden HF, Tosun S, Bayram A et al. Klinefelter syndrome: does it confer a bad prognosis in treatment of nonobstructive azoospermia? Fertil Steril 2011; 95: 1696-9.

70 Nagy P, Verheyen G, Tournaye H, Devroey P, van Steirteghem A. An improved treatment procedure for testicular biopsy offers more efficient sperm recovery: case series. Fertil Steril 1997; 68: 376-9

71 Crabbé E, Verheyen G, Silber S, Tournaye H, van de Velde $\mathrm{H}$ et al. Enzymatic digestion of testicular tissue may rescue the intracytoplasmic sperm injection cycle in some patients with non-obstructive azoospermia. Hum Reprod 1998; 13: 2791-6.

72 Carpi A, Sabanegh E, Mechanick J. Controversies in the management of nonobstructive azoospermia. Fertil Steril 2009; 91: 963-70

73 Verheyen G, Vernaeve V, van Landuyt L, Tournaye H, Devroey P et al. Should diagnostic testicular sperm retrieval followed by cryopreservation for later ICSI be the procedure of choice for all patients with non-obstructive azoospermia? Hum Reprod 2004; 19: 2822-30.

74 Vernaeve V, Verheyen G, Goosens A, van Steirteghem A, Devroey P et al. How successful is repeat testicular sperm extraction in patients with azoospermia? Hum Reprod 2006; 21: 1551-4.

75 Dalzell LH, McVicar CM, McClure N, Lutton D, Lewis SE. Effects of short and long incubations on DNA fragmentation of testicular sperm. Fertil Steril 2004; 82: 1443-5.

76 Nagy ZP, Chang CC, Shapiro DB, Bernal DP, Kort HI et al. The efficacy and safety of human oocyte vitrification. Semin Reprod Med 2009; 27: 450-5.

77 Osmanagaoglu K, Tournaye H, Camus M, Vandervorst M, van Steirteghem A et al. Cumulative delivery rates after intracytoplasmic sperm injection: 5 year follow-up of 498 patients. Hum Reprod 1999; 14: 2651-5.

78 Olivius K, Friden B, Lundin K, Bergh C. Cumulative probability of live birth after three in vitro fertilization/intracytoplasmic sperm injection cycles. Fertil Steril 2002; 77: $505-10$

79 Osmanagaoglu K, Tournaye H, Kolibianakis E, Camus M, van Steirteghem A et al. Cumulative delivery rates after ICSI in women aged $>37$ years. Hum Reprod 2002; 17: $940-4$.
80 Vernaeve V, Tournaye H, Osmanagaoglu K, Verheyen G, van Steirteghem A et al. Intracytoplasmic sperm injection with testicular spermatozoa is less successful in men with nonobstructive azoospermia than in men with obstructive azoospermia. Fertil Steril 2003; 79: 529-33.

81 Osmanagaoglu K, Vernaeve V, Kolibianakis E, Tournaye H, Camus M et al. Cumulative delivery rates after ICSI treatment cycles with freshly retrieved testicular sperm: a 7-year follow-up study. Hum Reprod 2003; 18: 1836-40.

82 Tournaye H. Intracytoplasmic sperm injection: a time bomb? In: de Jonge C, Barratt C, editors. Assisted Reproductive Technology: Accomplishments and Horizons. Cambridge: Cambridge University Press; 2002; 397-406.

83 Nikolettos N, Asimakopoulos B, Papastefanou IS. Intracytoplasmic sperm injectionan assisted reproduction technique that should make us cautious about imprinting deregulation. J Soc Gynecol Investig 2006; 13: 317-28.

84 Ponjaert-Kristoffersen I, Bonduelle M, Barnes J, Nekkebroeck J, Loft A et al. International collaborative study of intracytoplasmic sperm injection-conceived, in vitro fertilization-conceived, and naturally conceived 5-year-old child outcomes: cognitive and motor assessments. Pediatrics 2005; 115: e283-9.

85 Bonduelle M, Ponjaert I, Steirteghem AV, Derde MP, Devroey P et al. Developmental outcome at 2 years of age for children born after ICSI compared with children born after IVF. Hum Reprod 2003; 18: 342-50.

86 Bonduelle M, Liebaers I, Deketelaere V, Derde MP, Camus M et al. Neonatal data on a cohort of 2889 infants born after ICSI (1991-1999) and of 2995 infants born after IVF (1983-1999). Hum Reprod 2002; 17: 671-94.

87 Bonduelle M, Wilikens A, Buysse A, van Assche E, Devroey P et al. A follow-up study of children born after intracytoplasmic sperm injection (ICSI) with epididymal and testicular spermatozoa and after replacement of cryopreserved embryos obtained after ICSI. Hum Reprod 1998; 13 (Suppl 1): 196-207.

88 Wennerholm UB, Bergh C, Hamberger L, Westlander G, Wikland M et al. Obstetric outcome of pregnancies following ICSI, classified according to sperm origin and quality. Hum Reprod 2000; 15: 1189-94.

89 Wennerholm UB, Bonduelle M, Sutcliffe A, Bergh C, Niklasson A et al. Paternal sperm concentration and growth and cognitive development in children born with a gestational age more than 32 weeks after assisted reproductive therapy. Hum Reprod 2006; 21: 1514-20.

90 Belva F, de Schrijver F, Tournaye H, Liebaers I, Devroey P et al. Neonatal outcome of 724 children born after ICSI using non-ejaculated sperm. Hum Reprod 2011; 26: 1752-8.

91 Woldringh GH, Horvers M, Janssen AJ, Reuser JJ, de Groot SA et al. Follow-up of children born after ICSI with epididymal spermatozoa. Hum Reprod 2011; 26: 1759-67.

92 Silber S, Escudero T, Lenahan K, Abdelhadi I, Kilani Z et al. Chromosomal abnormalities in embryos derived from testicular sperm extraction. Fertil Steril 2003; 79: 30-8.

93 Bettio D, Venci A, Levi Setti P. Chromosomal abnormalities in miscarriages after different assisted reproduction procedures, Placenta 2008; 29 Suppl B: 126-8

94 Palermo G, Schlegel PN, Hariprashad JJ, Ergün B, Mielnik A et al. Fertilization and pregnancy outcome with intracytoplasmic sperm injection for azoospermic men. Hum Reprod 1999; 14: 741-8.

95 Ludwig M, Katalinic A. Malformation rate in fetuses and children conceived after ICSI: results of a prospective cohort study. Reprod Biomed Online 2002; 5: 171-8.

96 Vernaeve V, Bonduelle M, Tournaye H, Camus M, van Steirteghem A et al. Pregnancy outcome and neonatal data of children born after ICSI using testicular sperm in obstructive and non-obstructive azoospermia. Hum Reprod 2003; 18 : 2093-7 